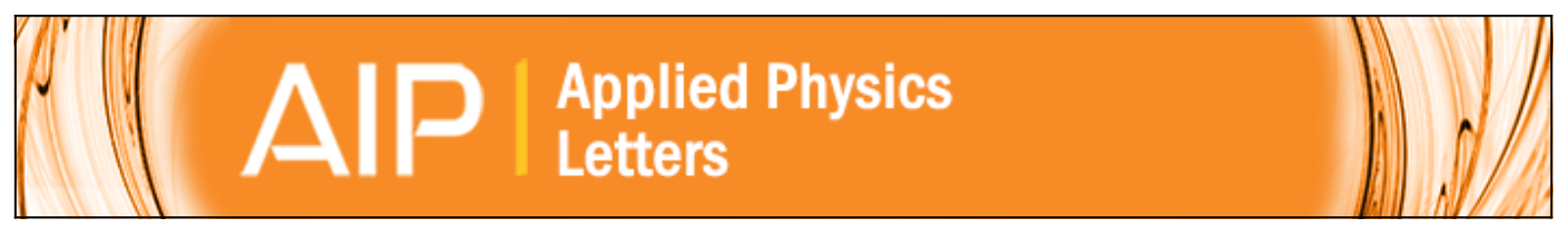

Femtosecond pulse generation in passively mode locked InAs quantum dot lasers

P. Finch, P. Blood, P. M. Smowton, A. Sobiesierski, R. M. Gwilliam, and I. O'Driscoll

Citation: Applied Physics Letters 103, 131109 (2013); doi: 10.1063/1.4822433

View online: http://dx.doi.org/10.1063/1.4822433

View Table of Contents: http://scitation.aip.org/content/aip/journal/apl/103/13?ver=pdfcov

Published by the AIP Publishing

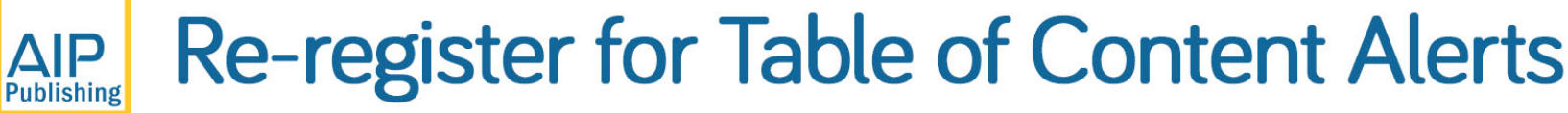

Create a profile.

Sign up today! 


\title{
Femtosecond pulse generation in passively mode locked InAs quantum dot lasers
}

\author{
P. Finch,,${ }^{1,2}$ P. Blood ${ }^{3}$ P. M. Smowton, ${ }^{3}$ A. Sobiesierski, ${ }^{3}$ R. M. Gwilliam, ${ }^{4}$ \\ and I. O'Driscoll ${ }^{1,2, a)}$ \\ ${ }_{1}^{1}$ Tyndall National Institute, Lee Maltings, Cork, Ireland \\ ${ }^{2}$ CAPPA, Cork Institute of Technology, Cork, Ireland \\ ${ }^{3}$ School of Physics and Astronomy, Cardiff University, Cardiff CF24 3AA, United Kingdom \\ ${ }^{4}$ Advanced Technology Institute, FEPS, University of Surrey, Guilford GU2 7XH, United Kingdom
}

(Received 28 June 2013; accepted 11 September 2013; published online 26 September 2013)

\begin{abstract}
Optical pulse durations of an InAs two-section passively mode-locked quantum dot laser with a proton bombarded absorber section reduce from 8.4 ps at $250 \mathrm{~K}$ to $290 \mathrm{fs}$ at $20 \mathrm{~K}$, a factor of 29 , with a corresponding increase in optical bandwidth. Rate equation analysis of gain and emission spectra using rate equations suggests this is due to the very low emission rate of carriers to the wetting layer in the low temperature, random population regime which enables dots across the whole inhomogeneous distribution to act as independent oscillators. (C) 2013 AIP Publishing LLC. [http://dx.doi.org/10.1063/1.4822433]
\end{abstract}

Ultrashort optical pulses facilitate a range of applications including high bit rate optical communications, ${ }^{1}$ wide gain bandwidth generation for wave division multiplexing, ${ }^{2}$ the generation of terahertz signal sources, ${ }^{3}$ optical clocking of electronic circuits, ${ }^{4}$ and, more recently, in biomedical applications for use in optical coherence tomography, ${ }^{5}$ nanosurgery, ${ }^{6}$ and microscopy and multiphoton imaging. ${ }^{7}$ Pulses may be created using passively mode locked quantum dots with an absorber within the lasing cavity. A key requirement for the generation of short pulses is a wide gain spectrum and rapid recovery of the absorber. Dots are ideal candidates for this purpose due to their large inhomogeneous distribution of dot sizes: a $1.3 \mu \mathrm{m}$ quantum dot laser, with a gain bandwidth of $50 \mathrm{~nm}$, could produce a transform-limited, mode locked pulse of just $30 \mathrm{fs}$. In practice, there are very limited examples of subpicosecond pulse generation using two-section quantum dot lasers (400 fs). ${ }^{8}$

At room temperature, the carriers on the dot states are in quasi-equilibrium with the wetting layer; ${ }^{9}$ their fractional occupation varies with their energy and this limits the width of the gain spectrum. Laser action occurs over a narrow line ${ }^{10,11}$ at the peak of the gain spectrum and additional current above threshold supplies this lasing process rather than increasing the population of dots of different sizes which further restricts the width of the available gain spectrum above threshold.

At low temperatures, dots are populated randomly, ${ }^{12}$ and the lasing spectra are much wider than at room temperature. ${ }^{10,11}$ The threshold current as a function of increasing temperature has a distinctive minimum at around $200 \mathrm{~K}$ as the dots go from random to quasi-equilibrium distributions. ${ }^{11,13}$ Since the random occupation probability is independent of energy, all dots become inverted at the same current, and the gain spectrum extends over the inhomogeneous width and follows the dot size distribution. Laser action first occurs at the peak of this spectrum, and additional current above threshold not only supplies a higher stimulated

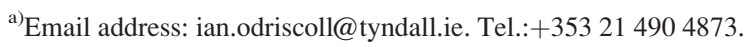

emission rate at the lasing dots but also increases the occupation of non-lasing dots so the lasing spectrum broadens. ${ }^{10,11}$ This suggests the pulse duration of mode-locked lasers could be reduced by operating in the random population regime, where the gain spectrum is wider, and the dots act as independent oscillators enabling this width to be accessed above threshold. The purpose of this paper is to explore this prospect: first the underlying physics, then reporting our modelocking results.

The occupation of dot states is brought about by carrier transport within the wetting layer and phonon-mediated exchange of carriers with the dots. ${ }^{14}$ At the dot densities necessary to achieve useful gain $\left(\sim 3 \times 10^{10} \mathrm{~cm}^{-2}\right)$, the limiting processes are capture and emission rather than carrier transport, ${ }^{15}$ and rate equations for interaction with a thermal phonon bath describe the transition from random to thermal regimes ${ }^{16}$ and give a good quantitative description of the temperature dependence of threshold current. ${ }^{17,18}$

Photoluminescence spectra provide valuable insight into carrier distributions; $;{ }^{19,20}$ however, to relate such observations directly to laser operation, we have used electrically pumped measurements of gain and calibrated spontaneous emission spectra on a device structure, ${ }^{21}$ which can be referenced to a known gain (the optical loss of the laser) to quantify the internal excitation. We observe that at temperatures below the minimum in threshold, the emission spectra broaden and analysis of the emission data at $20 \mathrm{~K}$ shows ground states in different size dots are populated with equal probability, increasing with drive current, indicative of random behaviour. ${ }^{18}$

We have compared this data with rate equation calculations of gain spectra for inhomogeneous distributions of ground and excited states, interacting via a thermal phonon bath with each other and with the wetting layer, and in which population of dots by electrons and holes is correlated, ${ }^{12,14,22}$ controlled by separation of the dot electron state from the wetting layer $(\sim 0.28 \mathrm{eV}$ for the ground state). Measured modal absorption spectra provided input values for the gain coefficient and spontaneous recombination lifetime (via the Einstein relations), which were temperature independent, 
and for the wetting layer band edge energy; energies and distributions of dot transitions were determined by Gaussian fits. The radiative threshold current density $J_{t h}(T)$ at fixed peak gain equal to the optical loss of the device was fitted to the measured radiative threshold current using only two adjustable parameters for the phonon coupling processes; there was no multiplicative scaling (see Ref. 18 for details).

Fig. 1 shows this fit and reciprocals of component emission and recombination times, indicating that in the calculation, the transition to random population below $200 \mathrm{~K}$ occurs because the emission rate to the wetting layer becomes many orders slower than the recombination rate. In the model, capture at the ground state occurs directly from the wetting layer and via excited states and in the steady state, the occupation probability is the ratio (total capture rate)/(capture plus recombination rate) which is independent of the energy of the state. Thus, at low temperature, once captured, carriers remain in the ground state till they recombine. They are not able to re-supply laser action at other dots via the wetting layer. Therefore, we expect that at temperatures below the minimum in $J_{t h}(T)$, where the phonon-induced emission is very slow, a wider gain spectrum is available above threshold.

Similar device structures were used for mode-locking experiments as used above for Fig. 1, grown using molecular beam epitaxy with five layers of InAs dots in an $\mathrm{In}_{0.15} \mathrm{Ga}_{0.85} \mathrm{As}$ well, with $\mathrm{GaAs}$ core and $\mathrm{Al}_{0.45} \mathrm{Ga}_{0.55} \mathrm{As}$ cladding waveguide. The gain and absorber sections were $1800 \mu \mathrm{m}$ and $200 \mu \mathrm{m}$ long, respectively. The gain section was driven with electrical pulses, width of $500 \mathrm{~ns}$, and duty cycle $8 \%$. The absorber was reverse biased with voltages ranging from $0 \mathrm{~V}$ to $5 \mathrm{~V}$. These devices show a minimum in threshold current as a function of temperature at about $250 \mathrm{~K}$ but mode-locking could not be observed below about $200 \mathrm{~K}$ due, we believe, to lengthening of the absorber recovery
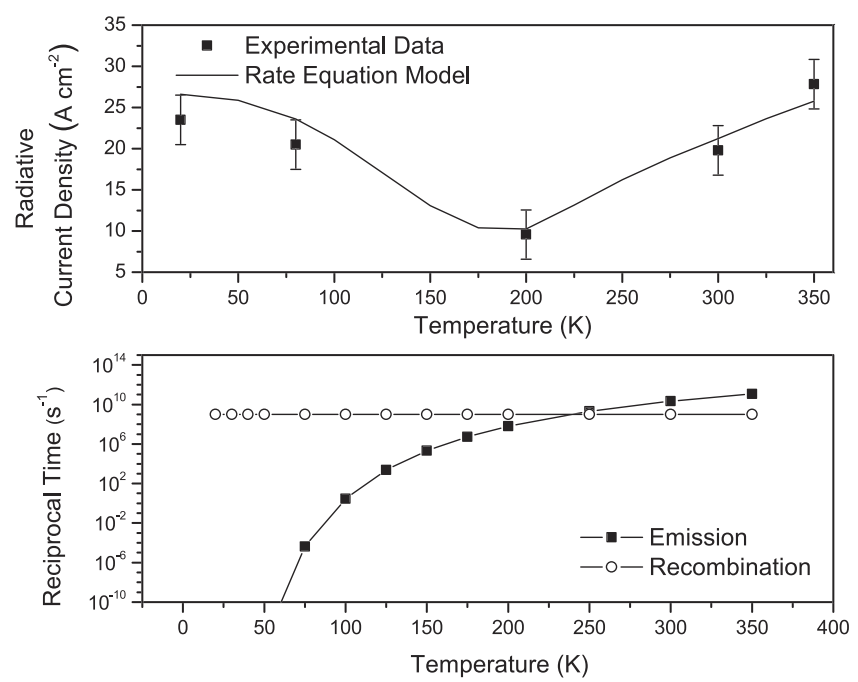

FIG. 1. Upper diagram shows the temperature dependence of radiative threshold current of a quantum dot laser emitting at $1.3 \mu \mathrm{m}$ (points) and a rate equation calculation (line). Reproduced with permission from I. O'Driscoll, P. Blood, and P. M. Smowton, IEEE J. Quantum Electron. 46(4), 525 (2010). Copyright 2010 IEEE Photonics Society. The lower diagram shows the reciprocals of the component ground state phonon-induced emission (solid squares) and radiative recombination times in a dot (open circles), the latter from measured absorption spectra via the Einstein relations.

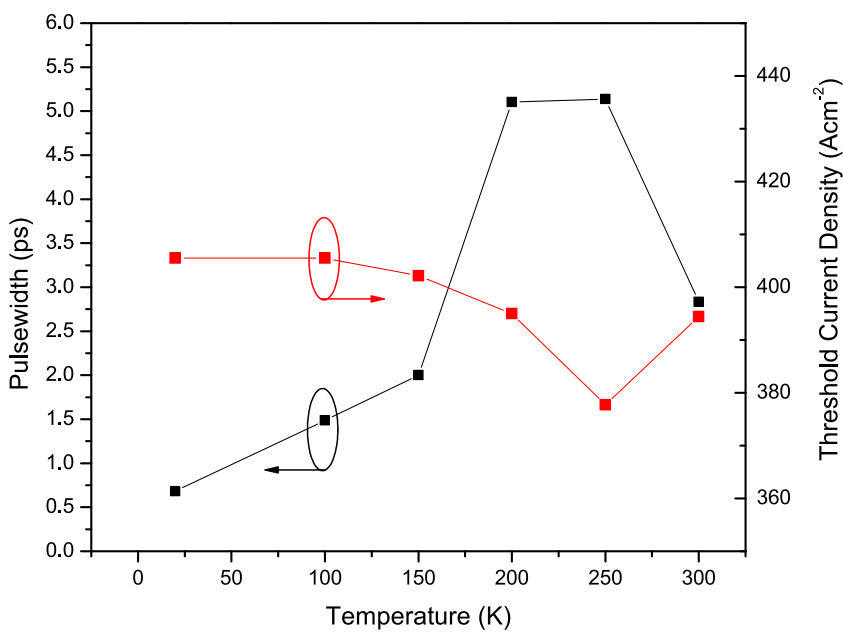

FIG. 2. Right y-axis: Experimentally measured threshold current densities $\left(\mathrm{J}_{\mathrm{th}}\right)$ for various temperatures with active and bombarded absorber sections pumped. Left y-axis: Experimentally measured pulsewidths at $2 \times \mathrm{J}_{\text {th }}$ with $2.5 \mathrm{~V}$ reverse bias for various temperatures on the bombarded absorber sample.

time. Carriers escaping to the wetting layer is the main mechanism by which they are lost from the dots ${ }^{14}$ and Fig. 1 shows that below about $225 \mathrm{~K}$ emission becomes slow and recovery is due to recombination alone.

To decrease the recovery time, we introduced nonradiative recombination centres into the absorber by proton bombardment at $250 \mathrm{keV}$, selected using standard range data, to produce a maximum number of displacements at the dot layers; a dose of $1 \times 10^{12} \mathrm{~cm}^{-2}$ was chosen based on the work in Ref. 23. The absorption peak was not shifted by bombardment, and transmission electron microscopy showed the integrity of the dots was retained. Time-resolved luminescence showed a factor ten faster decay at the transition energy, and analysis in Ref. 23 shows that defects are also introduced into the wetting layer, so at low temperatures, carriers can also be lost by tunnelling to nearby defect states. ${ }^{24}$ Mode-locking was observed in these devices with pulse widths reducing by a factor 29 from $8.4 \mathrm{ps}$ at $250 \mathrm{~K}$ to $290 \mathrm{fs}$ at $20 \mathrm{~K}$, and this correlates with the temperature dependence of threshold of the same structures, as shown in Fig. 2.

Optical spectra (Fig. 3) and pulsewidths (Fig. 4, FWHM obtained using $\operatorname{sech}^{2}$ functions) were measured using an

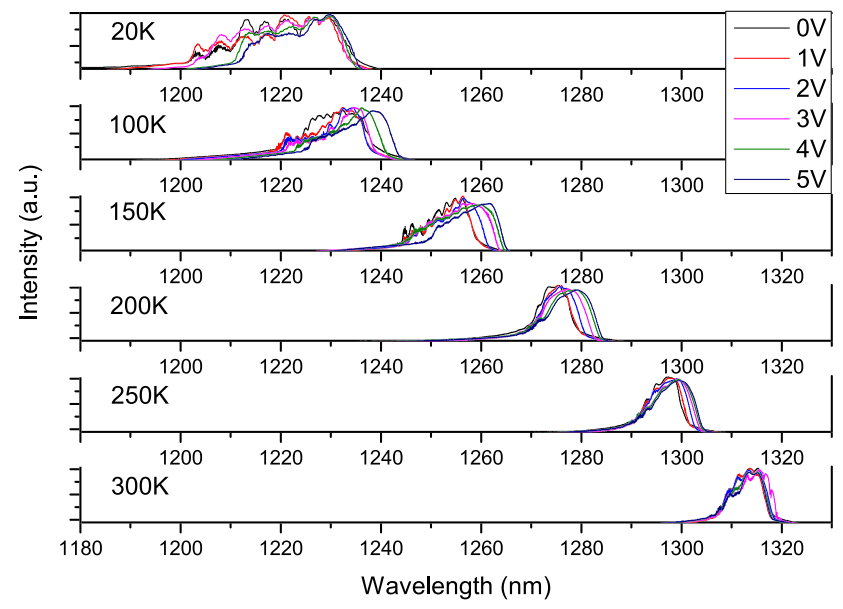

FIG. 3. Experimentally measured optical spectra for various temperatures at $770 \mathrm{~A} \mathrm{~cm}^{-2}$ for reverse biases of $0-5 \mathrm{~V}$ on the bombarded sample. 


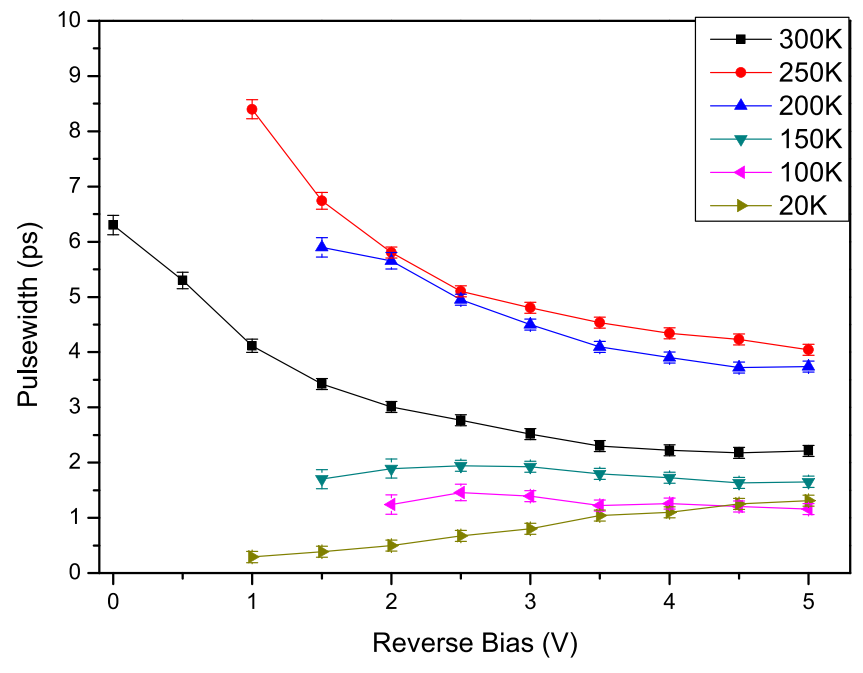

FIG. 4. Experimentally measured optical pulsewidths for increasing reverse bias and various temperatures at $770 \mathrm{~A} \mathrm{~cm}^{-2}$ on the bombarded sample.

Ando AQ6317 optical spectrum analyser and an APE Pulsecheck autocorrelator. With decreasing temperature, the available bandwidth (Fig. 3) decreases from about $8 \mathrm{~nm}$ at $300 \mathrm{~K}$ to a minimum at $250 \mathrm{~K}$ then increases to $30 \mathrm{~nm}$ at $20 \mathrm{~K}$. The pulse duration reduces from 4 ps ( $1 \mathrm{~V}$ bias $)$ at $300 \mathrm{~K}$ to $290 \mathrm{fs}$ at $20 \mathrm{~K}$ (Fig. 4). As the reverse bias is increased above $1 \mathrm{~V}$, the pulse durations increase due to a shifting of the absorption peak caused by the quantum confined Stark effect. ${ }^{25}$ Above threshold, the recombination rate is increased by stimulated emission, making it easier to satisfy the requirement that it exceeds the emission rate to the wetting layer (Fig. 1). Similar qualitative behaviour, over the range of temperatures investigated, was observed for a range of current densities.

We conclude that the optical pulse duration can be reduced by operating in the random regime, accessed in these experiments by reducing the temperature. Rate equation analysis of gain and emission data suggest that emission of carriers to the wetting layer becomes very slow at low temperature so that inversion can be maintained over the inhomogeneous width and the dots act as independent oscillators above threshold making a wide gain spectrum available. We believe that the slow emission rate also increases the absorber recovery time, and it is essential for mode-locking that this be overcome in our experiments by selective proton bombardment of the absorber section.

We recognise that low temperature mode-locking is not a commercially viable approach; nevertheless, these experiments establish the principle and point a way forward. The carrier escape rate is the key, and this can be reduced at room temperature using deeper dots with high energy barriers, ${ }^{26}$ and the minimum in threshold current can be shifted to higher temperature by doping. ${ }^{27}$ It may be possible to reduce the recovery time of the absorber by selective introduction of defects by diffusion from a surface oxide layer.

This research was based on the work supported by Science Foundation Ireland (SFI) under Grant No. 11/SIRG/ I2131 and Engineering Physical Sciences Research Councils (EPSRC) EP/F006683. The authors would like to thank M. Hopkinson for growing the material.

${ }^{1}$ W. H. Knox, IEEE J. Quantum Electron. 6(6), 1273 (2000).

${ }^{2}$ M. J. Guy, S. V. Chernikov, and J. R. Taylor, IEEE Photonics Technol. Lett. 9(7), 1017 (1997).

${ }^{3}$ J. Zhejing, L. Jiaren, L. Zhenguo, Z. Xiupu, P. J. Poole, P. J. Barrios, D. Poitras, and J. Caballero, IEEE Photonics Technol. Lett. 24(6), 518 (2012).

${ }^{4}$ G. A. Keeler, B. E. Nelson, D. Agarwal, C. Debaes, N. C. Helman, A. Bhatnagar, and D. A. B. Miller, IEEE J. Sel. Top. Quantum Electron. 9(2), 477 (2003).

${ }^{5}$ J. G. Fujimoto, C. Pitris, S. A. Boppart, and M. E. Brezinski, Neoplasia 2(1-2), 9 (2000).

${ }^{6}$ H. Lubatschowski, G. Maatz, A. Heisterkamp, U. Hetzel, W. Drommer, H. Welling, and W. Ertmer, Graefe's Arch. Clin. Exp. Ophthalmol. 238(1), 33 (2000).

${ }^{7}$ I. Pastirk, J. D. Cruz, K. A. Walowicz, V. V. Lozovoy, and M. Dantus, Opt. Express 11(14), 1695 (2003).

${ }^{8}$ E. U. Rafailov, M. A. Cataluna, W. Sibbett, N. D. Il'inskaya, Yu. M. Zadiranov, A. E. Zhukov, V. M. Ustinov, D. A. Livshits, A. R. Kovsh, and N. N. Ledentsov, Appl. Phys. Lett. 87(8), 081107 (2005).

${ }^{9}$ H. Summers, J. Thomson, P. M. Smowton, and P. Blood, Semicond. Sci. Technol. 16, 140 (2001).

${ }^{10}$ M. Sugawara, K. Mukai, and Y. Nakata, Appl. Phys. Lett. 74(11), 1561 (1999).

${ }^{11}$ A. Patane, A. Polimeni, H. Henini, L. Eaves, P. C. Main, and G. Hill, J. Appl. Phys. 85, 625 (1999).

${ }^{12}$ M. Grundmann and D. Bimberg, Phys. Rev. B 55, 9740 (1997).

${ }^{13}$ A. E. Zhukov, V. M. Ustinov, A. Y. Egorov, A. R. Kovsh, A. F. Tsatsul'nikov, N. N. Ledentsov, S. V. Zaitsev, N. Y. Gordeev, P. S. Kop'ev, and Z. I. Alferov, Jpn. J. Appl. Phys., Part 1 36, 4216 (1997).

${ }^{14}$ G. Gelinas, A. Lanacer, R. Leonelli, R. A. Masut, and P. J. Poole, Phys. Rev. B 81, 235426 (2010).

${ }^{15}$ C. Lobo, R. Leon, S. Marcinkevicius, W. Yang, P. Sercel, X. Liao, J. Zou, and D. Cockayne, Phys. Rev. B 60, 16647 (1999).

${ }^{16}$ H. D. Summers and P. Rees, J. Appl. Phys. 101, 073106 (2007).

${ }^{17}$ H. Huang and D. Deppe, IEEE J. Quantum Electron. 37, 691 (2001).

${ }^{18}$ I. O'Driscoll, P. Blood, and P. M. Smowton, IEEE J. Quantum Electron. 46(4), 525 (2010).

${ }^{19}$ S. Sanguinetti, M. Henini, M. G. Alessi, M. Capizzi, P. Frigeri, and S. Franchi, Phys. Rev. B 60, 8276-8283 (1999).

${ }^{20}$ P. Dawson, O. Rubel, S. D. Baranovskii, K. Pierz, P. Thomas, and E. O. Gobel, Phys. Rev. B 72, 235301 (2005).

${ }^{21}$ P. Blood, G. M. Lewis, P. M. Smowton, H. D. Summers, J. Thomson, and J. Lutti, IEEE J. Sel. Top. Quantum Electron. 9, 1275 (2003).

${ }^{22}$ S. Sanguinetti, D. Colombo, M. Guzzi, E. Grilli, M. Gurioli, L. Servalli, P. Frigeri, and S. Franchi, Phys. Rev. B 74, 205302 (2006).

${ }^{23}$ I. O'Driscoll, P. Blood, P. M. Smowton, A. Sobiesierski, and R. Gwilliam, Appl. Phys. Lett. 100, 261105 (2012).

${ }^{24}$ F. Guffarth, R. Heitz, M. Geller, C. M. A. Kapteyn, H. Born, R. L. Sellin, A. Hoffmann, D. Bimberg, N. A. Sobolev, and M. C. Carmo, Appl. Phys. Lett. 82, 1941 (2003).

${ }^{25}$ X. D. Huang, A. Stintz, H. Li, A. Rice, G. T. Liu, L. F. Lester, J. Cheng, and K. J. Malloy, IEEE J. Quantum Electron. 37(3), 414 (2001).

${ }^{26}$ L. Servalli, P. Frigeri, G. Trevisi, and S. Franchi, Appl. Phys. Lett. 92, 213104 (2008).

${ }^{27}$ P. M. Smowton, I. C. Sandall, D. J. Mowbray, H.-Y. Liu, and M. Hopkinson, IEEE J Sel. Top. Quantum Electron. 13, 1261 (2007). 